\title{
Prevalence, Types and Clinical Presentation of Heart Failure among Hypertensive Patients Seen at a Tertiary Hospital in Dar Es Salaam, Tanzania
}

\author{
Gervas George Nyaisonga, MD, MMED and Pilly Chillo, MD, MMED, PhD* (D) \\ Department of Internal Medicine, Muhimbili University of Health and Allied Sciences, Tanzania
}

*Corresponding author: Pilly Chillo, MD, MMED, PhD, Section of Cardiovascular Medicine, Department of Internal Medicine, Muhimbili University of Health and Allied Sciences, PO BOX 65001, Dar es Salaam, Tanzania, Tel: +255-22-2150603; +255-713-779781

\begin{abstract}
Background: Heart failure (HF) is a common complication in patients with hypertension who may present as HF with preserved ejection fraction (HFpEF) or HF with reduced ejection fraction (HFrEF). These categories have different clinical presentations and may require special attention to diagnose, especially when the presentation is HFpEF. The aim of this study was to assess the prevalence, types and clinical presentation of HF among hypertensive patients being followed-up at a tertiary hospital in Tanzania.

Methods: We included all known and newly diagnosed hypertensive adults ( $\geq 18$ years) referred for echocardiogram examination at the Muhimbili National Hospital - Mloganzila, between June and December 2019. A detailed cardiovascular history, physical, laboratory and echocardiogram examination was performed in all patients. HF was diagnosed according to the Framingham criteria and was further categorized as HFpEF (EF $\geq 50 \%$ ) or HFrEF (EF < 50\%), according to the echocardiography findings. Patients from these two groups were then compared in terms of demographic, clinical, laboratory and echocardiographic characteristics. The chi-square and Student's $t$ test was used to compare categorical and continuous data respectively. A p-value of < 0.05 indicated a statistically significant difference.

Results: Out of 633 hypertensive patients seen during the study period, $346(54.7 \%)$ fulfilled the inclusion criteria and were enrolled. Mean \pm SD age was $58.3 \pm 12.4$ years, and $60.4 \%$ were women. Mean \pm SD systolic and diastolic BP was $152 \pm 23$ and $91 \pm 15$, respectively. A total of 102 $(29.5 \%)$ patients were found to have HF. Three quarters of HF patients $(74.5 \%)$ had HFpEF and the remaining (25.5\%) had HFrEF. In comparison, patients with HFpEF were more likely to be outpatients, older, obese, and with higher mean $\mathrm{BP}$ and more concentric left ventricular hypertrophy when compared to those with HFrEF, all $p<0.05$.
\end{abstract}

Conclusion: The prevalence of HF among hypertensive patients seen at a tertiary hospital in Tanzania is $29.5 \%$, majority of them having HFpEF. HFpEF differs from HFrEF in terms of BP levels, obesity status and some echocardiographic parameters. These factors need to be carefully examined when HF is suspected in otherwise less symptomatic patients.

\section{Keywords}

Heart failure, Hypertension, Heart failure with preserved ejection fraction, Heart failure with reduced ejection fraction, Diastology, Echocardiogram, Sub Saharan Africa, Tanzania

\section{Introduction}

Heart failure (HF) is a global pandemic that affects approximately 64.3 million people worldwide [1], representing an important cause of morbidity and mortality [2]. The age-standardized prevalence rates of $\mathrm{HF}$ is increasing, and is accompanied with an increase in mortality and years lived with disability, especially in low and middle income countries (LMIC) [1]. The increasing $\mathrm{HF}$ burden is especially significant in sub Saharan Africa (SSA), including Tanzania, which is experiencing a change in epidemiology of diseases from communicable to non-communicable diseases [3]. Hypertension is by far the most common underlying cause contributing to the increase of HF burden in SSA [4], being present in $14.9 \%$ to $29.8 \%$ of the adult population $[5,6]$, and in up to $50 \%$ of those aged $\geq 55$ years [5]. Furthermore, hypertension in SSA is more severe and results in early end-organ damage, including $\mathrm{HF}$, chronic kidney dis-

\footnotetext{
Citation: Nyaisonga GG, Chillo P (2021) Prevalence, Types and Clinical Presentation of Heart Failure among Hypertensive Patients Seen at a Tertiary Hospital in Dar Es Salaam, Tanzania. Int J Clin Cardiol 8:230. doi.org/10.23937/2378-2951/1410230

Accepted: May 29, 2021: Published: May 31, 2021

Copyright: ( 2021 Nyaisonga GG, et al. This is an open-access article distributed under the terms of the Creative Commons Attribution License, which permits unrestricted use, distribution, and reproduction in any medium, provided the original author and source are credited.
} 
ease and stroke [7].

Regardless of the type, a diagnosis of HF carries a significant morbidity and mortality risk [8,9], and efforts should be made to diagnose HF earlier than later. With the aid of echocardiogram, HF has been classified into two major categories: HF with preserved ejection fraction (HFpEF) and HF with reduced ejection fraction (HFrEF) [10]. Among patients with hypertension, studies have found HFpEF to be more common, mainly due to diastolic dysfunction of the hypertrophied left ventricle $[11,12]$. HFpEF needs careful attention to diagnose, as traditionally HF was defined as a presence of reduced ejection fraction on echocardiogram. Ascertaining the proportion of hypertensive patients with HFpEF is important as it will increase awareness among clinicians of this otherwise obscured disease [13]. However, only few studies have reported on the types of HF among hypertensive patients in SSA $[8,14,15]$, and most of previous studies did not systematically look for HF symptoms therefore may have missed those with mild to moderate symptoms. Furthermore, no previous study in Tanzania has reported on the types of HF among exclusively hypertensive patients. This study was therefore set out to determine the prevalence, types and clinical characteristics of HF in a population of hypertensives attending a tertiary hospital in Tanzania.

\section{Methodology}

\section{Data collection process and definition of terms}

A structured questionnaire was used to collect patients' socio-demographic and clinical data. Information collected included gender, age of the patient, area of residence, cardiovascular risk factors, symptoms of HF, etc. A thorough physical examination was done and cardiovascular signs like ankle edema, upper quadrant abdominal tenderness, chest rales, S3 gallop, and jugular venous pulse were looked for and recorded whether present or not. The Framingham criteria was used to assess for the presence of HF among patients [16].

Blood pressure (BP) was measured according to guidelines [17], using a standard automated BP machine (Heuer Company, from USA). Hypertension was defined as systolic BP of $\geq 140 \mathrm{mmHg}$ and/or diastolic BP of $\geq 90$ $\mathrm{mmHg}$, or known hypertensive on medications, and was categorized as grade 1 (140-159/90-99 $\mathrm{mmHg})$, grade 2 (160-179/100-109 mmHg) and grade $3(\geq 180 / \geq 110$ $\mathrm{mmHg}$ ) according to European Society of Cardiology guidelines [17]. Height, weight, waist and hip circumferences were measured following standard guidelines.

For each patient, a $10 \mathrm{ml}$ of venous blood was collected and analyzed for cholesterol, glucose, creatinine, urea nitrogen and hemoglobin levels. High triglyceride levels were defined when serum triglyceride was $>1.69$ $\mathrm{mmol} / \mathrm{l}$, raised LDL-C was defined when serum LDL-C was $>3.34 \mathrm{mmol} / \mathrm{l}$, high total cholesterol was defined when serum total cholesterol was $>5.2 \mathrm{mmol} / \mathrm{l}$ and low HDL-C was defined when serum HDL-C was $<1.04$ $\mathrm{mmol} / \mathrm{l}$, according to the Muhimbili National Hospital's laboratory reference values. Estimated glomerular filtration rate (eGFR) was calculated from CKD-EPI equations [18] and renal dysfunction was considered to be present when a patient had eGFR of less than $60 \mathrm{ml} /$ $\mathrm{min} / 1.73 \mathrm{~m}^{2}$. Anemia was defined as hemoglobin of less than $13 \mathrm{~g} / \mathrm{dl}$ in men and $12 \mathrm{~g} / \mathrm{dl}$ in women according to the World Health Organization [19].

Echocardiograms were performed using a General Electric (GE) Vivid S3 echocardiogram machine equipped with a $3.5 \mathrm{MHZ}$ transducer, and the protocol followed the American Society of Echocardiology recommendations [20]. Left ventricular (LV) hypertrophy (LVH) was considered present when LV mass (LVM) indexed to body surface area (LVMI) was $>95 \mathrm{~g} / \mathrm{m}^{2}$ in women and $>115 \mathrm{~g} / \mathrm{m}^{2}$ in men. LVEF was determined using M-mode guided parasternal long-axis images of the left ventricle and was taken as a measure of LV systolic function. EF of $<50 \%$ was considered as systolic dysfunction [20]. LV filling was obtained by determining peak early velocity (E) at the level of the mitral leaflets' tips, and the medial early diastolic mitral annular velocity $\left(E^{\prime}\right)$ was measured by spectral tissue Doppler imaging in apical four-chamber views. The ratio of $E$ to $E^{\prime}$ velocity ( $E / E^{\prime}$ ratio) was taken as an estimation of LV filling pressure and diastolic dysfunction was considered present when the $E / E^{\prime}$ was $\geq 15$ [21].

Patients with HF as per Framingham criteria were further categorized as HFrEF (when EF < 50\%) or HFpEF (EF $\geq 50 \%$ ) [10]. The diagnosis of HFpEF required the following conditions to be satisfied: (i) Positive diagnosis of $\mathrm{HF}$ as per Framingham criterion; (ii) LV EF $\geq 50 \%$; (iii) $L V$ diastolic dysfunction, i.e. $E / E^{\prime} \geq 15$. The diagnosis of HFrEF was reached when the following conditions were satisfied (i) Positive diagnosis of HF as per Framingham criterion and (ii) Reduced LV systolic function on echocardiogram (i.e. LV ejection < 50\%) [10].

\section{Data handling and analysis}

All questionnaires were scanned for completeness and coded before being entered into the dataset. Statistical package of Social Science for Windows (SPSS) version 21 was used for statistical analysis. Continuous variables were expressed as the mean \pm SD, and categorical variables as $n(\%)$. The $\chi^{2}$ or Fisher's exact test was used to compare categorical variables, as appropriate. Student's $t$ test was used to compare the mean values. For statistical tests a two-tailed $p$-value $<0.05$ was considered significant.

\section{Ethical considerations}

This study was conducted in accordance with the Helsinki Declaration of studies on human subjects. Ethical approval to conduct the study was obtained from 
Table 1: Demographic, clinical and laboratory characteristics of the study population.

\begin{tabular}{|c|c|}
\hline Variable & n (\%) or mean \pm SD \\
\hline Mean \pm SD Age (years) & $58.3 \pm 12.4$ \\
\hline \multicolumn{2}{|l|}{ Age Categories, n (\%) } \\
\hline $18-40$ & $28(8.1)$ \\
\hline $41-54$ & $100(28.9)$ \\
\hline$\geq 55$ & $218(63)$ \\
\hline Female Sex, n (\%) & $209(60.4)$ \\
\hline \multicolumn{2}{|l|}{ Place Of Referral, n (\%) } \\
\hline Outpatient & $305(88.1)$ \\
\hline Inpatient & $41(11.9)$ \\
\hline \multicolumn{2}{|l|}{ Cardiovascular Risk Factors, n (\%) } \\
\hline Diabetes & $44(12.7)$ \\
\hline Smoking & $34(9.8)$ \\
\hline Alcohol & $146(42.2)$ \\
\hline Family History of Cardiovascular Disease & $152(43.9)$ \\
\hline \multicolumn{2}{|l|}{ Anthropometric Variables } \\
\hline Mean \pm SD Height $(\mathrm{cm})$ & $165.2 \pm 9.2$ \\
\hline Mean \pm SD Weight $(k g)$ & $75.9 \pm 16.2$ \\
\hline Mean \pm SD BMI $\left(\mathrm{kg} / \mathrm{m}^{2}\right)$ & $27.8 \pm 5.3$ \\
\hline \multicolumn{2}{|l|}{ Obesity Status, n (\%) } \\
\hline Normal Weight & $127(36.7)$ \\
\hline Overweight & $113(32.7)$ \\
\hline Obese & $106(30.6)$ \\
\hline Mean \pm SD Duration of hypertension & $6.8 \pm 9.1$ \\
\hline Mean \pm SD Systolic BP $(\mathrm{mmhg})(\mathrm{mmhg})$ & $152 \pm 23$ \\
\hline Mean \pm SD Diastolic BP (mmhg) & $91 \pm 15$ \\
\hline \multicolumn{2}{|l|}{ Hypertension Stage, $\mathbf{n}(\%)$} \\
\hline Normal (Controlled) BP & $100(28.9)$ \\
\hline Stage 1 & $98(28.3)$ \\
\hline Stage 2 & $85(24.6)$ \\
\hline Stage 3 & $63(18.2)$ \\
\hline Mean \pm SD Pulse Rate (beats/min) & $80 \pm 15$ \\
\hline Tachycardia ( $\geq 100 \mathrm{~b} / \mathrm{min}), \mathrm{n}(\%)$ & $47(13.6)$ \\
\hline \multicolumn{2}{|l|}{ Laboratory Findings } \\
\hline Mean \pm SD Triglyceride $(\mathrm{mmol} / \mathrm{L})$ & $1.5 \pm 0.7$ \\
\hline Raised Triglyceride, n (\%) & $120(34.7)$ \\
\hline Mean \pm SD Cholesterol (mmol/L) & $5.3 \pm 3.4$ \\
\hline Raised Cholesterol, n (\%) & $165(47.7)$ \\
\hline Mean \pm SD LdL-C (mmol/L) & $3.6 \pm 1.2$ \\
\hline Raised LDL-C, n (\%) & $202(58.4)$ \\
\hline Mean \pm SD HdL-C (mmol/L) & $1.1 \pm 0.2$ \\
\hline Low HDL-C, N (\%) & $154(44.5)$ \\
\hline Mean \pm Hemoglobin $(\mathrm{g} / \mathrm{dl})$ & $12.6 \pm 2$ \\
\hline Anemia, n (\%) & $110(31.8)$ \\
\hline Mean \pm SD eGFR $\left(\mathrm{ml} / \mathrm{min} / 1.73 \mathrm{~m}^{2}\right)$ & $72.7 \pm 22$ \\
\hline Mean \pm SD Urea Nitrogen (mmol/L) & $10.9 \pm 7.7$ \\
\hline Proportion With Renal Dysfunction, n (\%) & $85(24.5)$ \\
\hline
\end{tabular}

BMI: Body Mass Index; BP: Blood Pressure; LDL: Low Density Lipoprotein; HDL: High Density Lipoprotein; eGFR: Estimated Glomerular Filtration Rate 
the Directorate of Research and Publications of the Muhimbili University of Health and Allied Sciences. All patients had to sign an informed consent form before any data was collected.

\section{Results}

\section{Socio-demographic and clinical findings}

Three hundred and forty six (54.7\%) out of 633 hypertensive patients that were screened fulfilled the inclusion and exclusion criteria and were enrolled. Of those excluded, 88 did not give consent, 12 were pregnant, 16 were admitted in the Intensive Care Unit and 171 were referred more than once. Table 1 shows the socio-demographic and clinical characteristics of the study participants. The mean age of the total studied population was 58.3 years (range 28-89 years). Majority $(88.1 \%)$ of participants were from outpatient clinics. Obesity was present in $30.6 \%$ of the participants. The mean \pm SD systolic and diastolic blood pressure in the total population was $152 \pm 23 \mathrm{mmHg}$ and $91 \pm 15 \mathrm{mmHg}$ respectively, and those with stage 3 hypertension were $18.2 \%$. Anemia was present in $31.3 \%$ of the total population, and $24.5 \%$ had renal dysfunction.

Figure 1 shows the drugs used by study patients, while the symptoms and signs of HF experienced by study patients are shown in Table 2. Antihypertensives receptor blockers were the most used antihypertensive (39\%), followed by calcium channel blockers (34.7\%), thiazide diuretics (25.7\%) and beta blockers (9.5\%).

Echocardiogram findings of the study patients are shown in Table 3. As seen in the table, more than half (52.9\%) of the total studied had LVH, $9.5 \%$ had LV systolic dysfunction, and $20.5 \%$ had LV diastolic dysfunction.

\section{Prevalence of HF}

One hundred and eight out of the 346 studied population fulfilled the Framingham criteria for HF. Among the 108 patients who met clinical criteria for HF, 26 had $\mathrm{EF}<50 \%$, while 82 had $\mathrm{EF} \geq 50 \%$ in echocardiogram. Of the 82 participants with clinical $\mathrm{HF}$ and $\mathrm{EF} \geq 50 \%, 6$ did not meet the echocardiographic definition of diastolic dysfunction and therefore they did not have HF, leaving $102 / 346(29.5 \%)$ as the true prevalence of HF in this population. Among 102 patients with $\mathrm{HF}, 76(74.5 \%)$ had HFpEF and the remaining 26 (25.5\%) had HFrEF (Figure 2).

Table 2: Symptoms and signs of HF among study patients.

\begin{tabular}{|l|l|l|}
\hline Variable & n & (\%) \\
\hline Symptoms & & \\
\hline Shortness of breath & 185 & 53.5 \\
\hline Palpitation & 182 & 52.6 \\
\hline Lower limb swelling & 132 & 38.2 \\
\hline Nocturnal cough & 65 & 18.8 \\
\hline Orthopnea & 47 & 13.6 \\
\hline Paroxysmal nocturnal dyspnea & 34 & 9.8 \\
\hline Right upper quadrant pain & 7 & 2 \\
\hline Signs & & \\
\hline Lower limb edema & 69 & 19.9 \\
\hline Gallop & 24 & 6.9 \\
\hline Shift of apex beat & 16 & 4.6 \\
\hline Raised jugular venous pressure & 8 & 2.3 \\
\hline Heaving apex beat & 19 & 5.5 \\
\hline Basal crepitation & 10 & 2.9 \\
\hline Tenderness of right upper quadrant & 4 & 1.2 \\
\hline & & \\
\hline
\end{tabular}

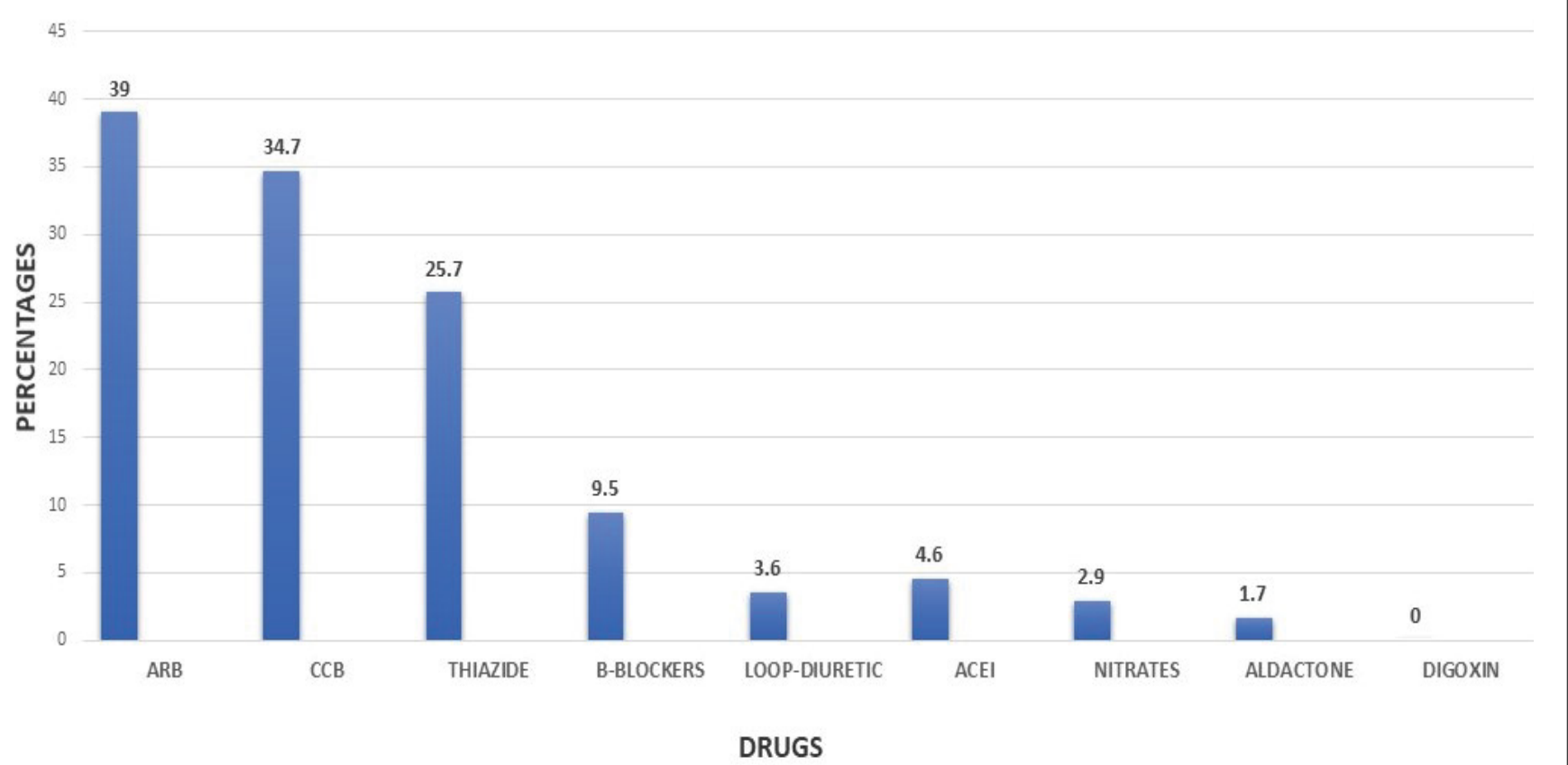

Figure 1: Types of drugs used by hypertensive patients.

ARB: Angiotensin Receptor Blocker; CCB: Calcium Channel Blocker; ACEI: Angiotensin Converting Enzyme Inhibitor 


\section{Comparison between hypertensive patients with HFpEF and HFrEF}

Patients with HFpEF were more likely to be outpatients and showed a trend of being older than patients with HFrEF. In terms of symptoms and signs, patients with HFpEF were less likely to have paroxysmal nocturnal dyspnoea, shifted apex beat, gallop rhythm and basal crepitations, all $p<0.05$ (Table 4). In terms of echocardiographic findings, patients with HFpEF were having

Table 3: Echocardiographic findings of the study population.

\begin{tabular}{|l|l|}
\hline Variable & $\begin{array}{l}\text { n (\%) or mean } \\
\mathbf{\pm} \text { SD }\end{array}$ \\
\hline Interventricular Septum in Diastole (cm) & $1.18 \pm 0.2$ \\
\hline LV Posterior Wall in Diastole (cm) & $1.12 \pm 0.3$ \\
\hline LV Internal Diameter in Diastole (cm) & $4.6 \pm 0.7$ \\
\hline LV Mass Index (g/m²) & $111.1 \pm 37.3$ \\
\hline Proportion with LV Hypertrophy & $183(52.9)$ \\
\hline Fractional Shortening (\%) & $37.7 \pm 8.6$ \\
\hline EF (\%) & $66.8 \pm 12.4$ \\
\hline Proportion with Reduced EF & $33(9.5)$ \\
\hline Left Atrial Diameter (cm) & $3.8 \pm 0.6$ \\
\hline Left Atrial Volume Index (ml/m²) & $30 \pm 12$ \\
\hline Proportion with Left Atrial Enlargement & $97(28)$ \\
\hline E (m/s) & $0.6 \pm 0.2$ \\
\hline A (m/s) & $0.75 \pm 0.1$ \\
\hline E/A Ratio & $0.9 \pm 0.5$ \\
\hline Deceleration Time (ms) & $155 \pm 62.1$ \\
\hline Isovolumic Relaxation Time (ms) & $101 \pm 22$ \\
\hline E' (m/s)) & $0.08 \pm 0.2$ \\
\hline E/E' Ratio & $12 \pm 22$ \\
\hline Proportion with E/E' $\geq 15$ & $71(20.5)$ \\
\hline
\end{tabular}

LV: Left Ventricular; EF: Ejection Fraction significantly more concentric LV geometry, while those found to have HFrEF had significantly higher left atrial volume index as well as left ventricle internal diameter, indicating larger LV dimensions all $p<0.05$ (Table 4).

\section{Discussion}

$\mathrm{HF}$ is a common complication of hypertension, and its burden may be higher in SSA due to the increased hypertension prevalence $[5,6]$, late hospital presentation [3] and limited ability to diagnose the early disease [1]. In this cross-sectional study of hypertensive patients attending a referral hospital in Tanzania, we highlight 3 important findings that add to the current knowledge of hypertensive heart disease in the region. First, the prevalence of $\mathrm{HF}$ among hypertensive patients seen at a referral hospital in Tanzania is $29.5 \%$; second, majority of hypertensive patients with HF have HFpEF; and third, hypertensive patients with HFpEF differ from those with HFrEF in a number of demographic and clinical characteristics.

The prevalence of $\mathrm{HF}$ found in this study is in keeping with the findings from a meta-analysis of 23 blood pressure-lowering clinical trials involving 193,424 hypertensives, in whom HF occurred in $28.9 \%$ [22]. The present findings also echo our understanding that hypertension is the most common underlying risk factor for $\mathrm{HF}$ in SSA accounting up to $45 \%$ of HF cases [4]. In population studies, hypertension confers a 2-3 folds increased hazard to HF development [23], indicating very strong links between hypertension and HF. The mechanism of $\mathrm{HF}$ in hypertension has been termed to involve chronic pressure overload that leads to the development of left ventricular hypertrophy and fibrotic changes that lead to progressive diastolic dysfunction and failure, while another subset of patients progresses to systolic dysfunction in the presence of chronic volume and pres-

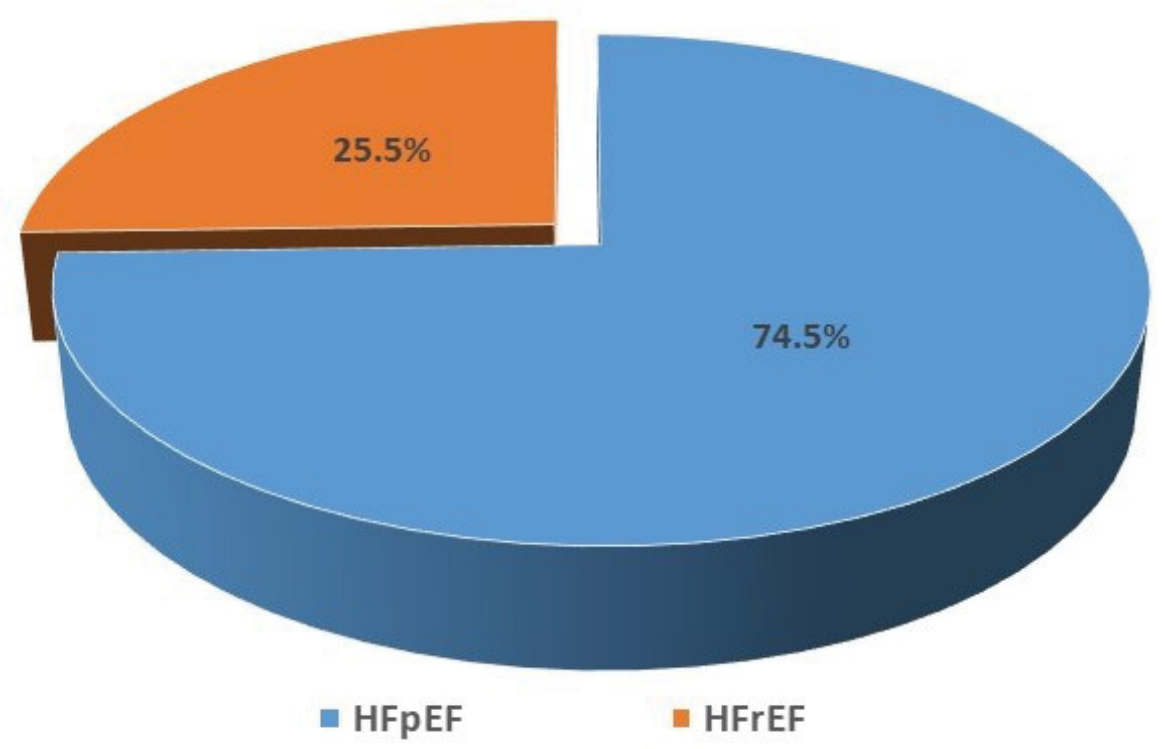

Figure 2: Distribution of HFpEF and HFrEF among hypertensive patients with HF. 
Table 4: Comparison between hypertensive patients with HFpEF and HFrEF.

\begin{tabular}{|c|c|c|c|}
\hline Variables & $\begin{array}{l}\text { HFpEF } \\
n=76\end{array}$ & $\begin{array}{l}\text { HFrEF } \\
n=26\end{array}$ & $p$ value \\
\hline Mean \pm SD age (years) & $61 \pm 11$ & $57 \pm 14$ & 0.113 \\
\hline Age $\geq 55$ years, $\mathrm{n}(\%)$ & $57(75)$ & $14(53.8)$ & 0.023 \\
\hline Women, n (\%) & $49(64.5)$ & $15(58)$ & 0.64 \\
\hline Inpatients, n (\%) & $14(18.4)$ & $11(42.3)$ & 0.02 \\
\hline Diabetes, n (\%) & $10(13.2)$ & $6(23.1)$ & 0.348 \\
\hline \multicolumn{4}{|l|}{ Symptoms, n (\%) } \\
\hline Shortness of breath & $68(89.5)$ & $25(96.2)$ & 0.442 \\
\hline Palpitation & $48(63.2)$ & $16(61.5)$ & 0.912 \\
\hline Orthopnea & $51(67.1)$ & $18(69.2)$ & 0.987 \\
\hline PND & $17(22.4)$ & $15(57.7)$ & 0.001 \\
\hline Lower limb swelling & $48(63.2)$ & $15(57.7)$ & 0.367 \\
\hline Right upper quadrant pain & $3(4)$ & $3(11.4)$ & 0.334 \\
\hline Nocturnal cough & $42(55.3)$ & $20(76.9)$ & 0.051 \\
\hline \multicolumn{4}{|l|}{ Physical findings } \\
\hline Mean \pm SD Pulse rate (beats/min) & $79 \pm 18$ & $86 \pm 17$ & 0.063 \\
\hline Mean \pm SD SBP $(\mathrm{mmHg})$ & $157 \pm 23$ & $142 \pm 28$ & 0.011 \\
\hline Mean \pm SD DBP $(\mathrm{mmHg})$ & $92 \pm 23$ & $89 \pm 17$ & 0.258 \\
\hline Mean \pm SD BMI $\left(\mathrm{kg} / \mathrm{m}^{2}\right)$ & $29 \pm 6.4$ & $26.2 \pm 6.6$ & 0.058 \\
\hline Obesity, n (\%) & $33(43.4)$ & $6(23.1)$ & 0.001 \\
\hline \multicolumn{4}{|l|}{ Signs, n (\%) } \\
\hline Raised JVP & $6(7.9)$ & $3(11.5)$ & 0.690 \\
\hline Shifted Apex beat & $13(17.1)$ & $12(46.2)$ & 0.005 \\
\hline Gallop rhythm & $11(14.5)$ & $20(76.9)$ & 0.000 \\
\hline Basal crepitation & $3(3.9)$ & $7(26.9)$ & 0.002 \\
\hline Lower limb edema & $30(39.5)$ & $13(50)$ & 0.367 \\
\hline \multicolumn{4}{|l|}{ Laboratory findings } \\
\hline Mean \pm SD Hemoglobin (g/dl) & $12.4 \pm 1.6$ & $11.6 \pm 2$ & 0.001 \\
\hline Mean \pm SD Creatinine $(\mu \mathrm{mol} / \mathrm{l})$ & $121.5 \pm 87$ & $130.7 \pm 117$ & 0.11 \\
\hline Mean \pm SD BUN $(\mathrm{mmol} / \mathrm{l})$ & $12 \pm 12.7$ & $12.2 \pm 8.8$ & 0.15 \\
\hline Mean \pm SD eGFR $\left(\mathrm{ml} / \mathrm{min} / 1.73 \mathrm{~m}^{2}\right)$ & $68.6 \pm 24$ & $70.6 \pm 30$ & 0.204 \\
\hline Renal dysfunction, n (\%) & $22(28.9)$ & $10(38.5)$ & 0.463 \\
\hline \multicolumn{4}{|l|}{ Echocardiographic findings } \\
\hline Interventricular septum in diastole $(\mathrm{cm})$ & $1.35 \pm 0.2$ & $1.1 \pm 0.3$ & 0.001 \\
\hline LV internal diameter in diastole $(\mathrm{cm})$ & $4.6 \pm 0.6$ & $5.6 \pm 0.8$ & 0.000 \\
\hline Left atrial volume index $\left(\mathrm{ml} / \mathrm{m}^{2}\right)$ & $32.5 \pm 12$ & $43.4 \pm 16$ & 0.001 \\
\hline Proportion with LVH, n (\%)s & $57(75)$ & $22(84.6)$ & 0.419 \\
\hline Proportion with enlarged LA n (\%) & $32(42.1)$ & $16(61.5)$ & 0.112 \\
\hline Mean \pm SD E/E' & $15.8 \pm 5$ & $20.9 \pm 11$ & 0.002 \\
\hline
\end{tabular}

BMI: Body Mass Index; PND: Paroxysmal Nocturnal Dyspnea; JVP: Jugular Venous Pressure; n: Number; SD: Standard Deviation, HFpEF: Heart Failure with Preserved Ejection Fraction; HFrEF: Heart Failure with Reduced Ejection Fraction

sure overload [24].

Our finding that majority of patients with hypertensive HF have HFpEF is similar to many previous studies that studied hypertensive-only HF cohorts [25-27], and underscores the importance of diastolic HF in this population. However, Ogah, et al. found a $35 \%$ proportion of HFpEF in a hypertensive HF registry in Nigeria contrary to the current findings [15]. The difference between ours and the study by Ogah is likely due to the differences in the study population, as HF registry tend to include patients with end stage hypertensive heart disease, where those with diastolic dysfunction progress to have LV dilatation and eventual systolic dysfunction at the end of the hypertensive heart disease spectrum 
[24]. Nevertheless, active search for HF among hypertensive patients is recommended [21] as most of the patients with HFpEF could have been missed if only ejection fraction was used to categorize HF. Of note, the diagnosis of $\mathrm{HFpEF}$ is tricky and it requires thorough assessment of diastolic function to determine presence of increased LV filling pressures [13]. Our definition of diastolic dysfunction as $E / E^{\prime}$ of $\geq 15$ indicate marked raise in LV filling pressures, and therefore true diastolic dysfunction. Of note, these patients had similar proportion of dyspnea which is the hallmark of HF, similar to patients with HFrEF (Table 4). As suggested by guidelines, patients with diastolic HF require similar medications and follow-up as for those with HFrEF [25].

In this study, hypertensive patients found to have HFpEF were more likely to be older adults ( $\geq 55$ years), obese and with higher mean systolic BP when compared to those with HFrEF. These findings are similar to current knowledge of this subset of HF patients $[8,12,27]$, and our findings confirms this observation also among native Tanzanian hypertensives. However, other risk factors including diabetes mellitus and female gender did not show significant associations as previously reported $[8,28-30]$, most likely due to the fact that the current study was not powered to detect these associations, and only trends could be seen. Not surprisingly, clinical signs of shifted apex beat, gallop rhythm, basal crepitations which signify more volume overload were more frequently seen in HFrEF when compared to the group found to have HFpEF, in keeping with previous studies in literature [26].

As expected, patients with HFpEF had more concentric LV geometry on echocardiogram, which is the underlying cause of diastolic dysfunction in hypertensive patients [31]. Of note, while the mean LA volume was high in both groups, those with HFrEF had higher volumes, indicating that patients with HFrEF are at the end spectrum of hypertensive HF, and they are likely to have passed the LV diastolic dysfunction before progressing to HFrEF [32]. This is also confirmed by the higher mean $E / E^{\prime}$ in the HFrEF group. In short, patients with HFrEF also have diastolic dysfunction while patients with HFpEF have diastolic dysfunction without systolic dysfunction, confirming the notion that diastolic and systolic HF are not independent or separate entities, rather HF is a single continuous disease spectrum and systolic and diastolic HF are phenotypes at two extremes; as advocated by the single syndrome hypothesis of HF [32].

The strength of this study include its prospective nature which allowed for objective and thorough assessment of clinical and echocardiographic parameters, therefore likely to have captured most of hypertensive patients with HF. We did not systematically determine biomarkers of HF like NT-Pro BNP levels in this study, therefore it is possible that some of the HF symptoms could have been due to other conditions like chronic obstructive pulmonary disease. However, the use of the Framingham criteria together with echocardiogram must have offset most of these biases.

\section{Conclusion}

In conclusion, the prevalence of $\mathrm{HF}$ among hypertensive patients being followed-up at a tertiary hospital in Tanzania is high, and the majority of patients with $\mathrm{HF}$ present as HFpEF. We recommend active screening for HF especially in the obese, elderly and uncontrolled hypertensive patients, as they may present with HFpEF which can pass unnoticed.

\section{Disclosure Statement}

The authors report no conflicts of interest.

\section{Funding Details}

Not applicable.

\section{Competing Interests}

The authors declare that they have no competing interests.

\section{Availability of Data and Materials}

The datasets used and/or analyzed during the current study are available from the corresponding author on reasonable request.

\section{Authors' Contributions}

GN and PC conceived the research idea. GN recruited patients and did data entry. GN and PC performed echocardiogram, analyzed and interpret data. Both authors drafted the manuscript, have read and approved the final manuscript.

\section{Acknowledgements}

We extend our gratitude to all the study participants for their cooperation offered during this study. Special thanks to Doctor Emmanuel Matulo, Sr. Rose and Sr. Sophia whose work on data collection, recruitment and disposal of patients cannot go unmentioned.

\section{References}

1. Bragazzi NL, Zhong W, Shu J, Abu Much A, Lotan D, et al. (2021) Burden of heart failure and underlying causes in 195 countries and territories from 1990 to 2017. European Journal of Preventive Cardiology 12.

2. Jones NR, Roalfe AK, Adoki I, Hobbs FDR, Taylor CJ (2019) Survival of patients with chronic heart failure in the community: A systematic review and meta-analysis. Eur $\mathrm{J}$ Heart Fail 21: 1306-1325.

3. Agbor VN, Essouma M, Ntusi NAB, Nyaga UF, Bigna JJ, et al. (2018) Heart failure in sub-Saharan Africa: A contemporaneous systematic review and meta-analysis. Int $\mathrm{J}$ Cardiol 257: $207-215$.

4. Damasceno A, Mayosi BM, Sani M, Ogah OS, Mondo C, et al. (2012) The causes, treatment, and outcome of acute heart failure in 1006 Africans from 9 countries. Arch Intern Med 172: 1386-1394. 
5. Hendriks ME, Wit FW, Roos MT, Brewster LM, Akande TM, et al. (2012) Hypertension in sub-Saharan Africa: Cross-sectional surveys in four rural and urban communities. PLoS One 7: e32638.

6. Guwatudde D, Nankya-Mutyoba J, Kalyesubula R, Laurence C, Adebamowo C, et al. (2015) The burden of hypertension in sub-Saharan Africa: A four-country cross sectional study. BMC Public Health 15: 1211.

7. Yoruk A, Boulos PK, Bisognano JD (2018) The state of hypertension in Sub-Saharan Africa: Review and Commentary. Am J Hypertens 31: 387-388.

8. Abebe TB, Gebreyohannes EA, Tefera YG, Abegaz TM (2016) Patients with HFpEF and HFrEF have different clinical characteristics but similar prognosis: A retrospective cohort study. BMC Cardiovasc Disord 16: 232.

9. Magnussen C, Niiranen TJ, Ojeda FM, Gianfagna F, Blankenberg S, et al. (2019) Sex-specific epidemiology of heart failure risk and mortality in Europe: Results From the BiomarCaRE Consortium. JACC Heart Fail 7: 204-213.

10. Paulus WJ, Tschope C, Sanderson JE, Rusconi C, Flachskampf FA, et al. (2007) How to diagnose diastolic heart failure: $A$ consensus statement on the diagnosis of heart failure with normal left ventricular ejection fraction by the Heart Failure and Echocardiography Associations of the European Society of Cardiology. Eur Heart J 28: 25392550.

11. Sun JP, Xu TY, Lee AP, Yang XS, Liu M, et al. (2015) Early diastolic dyssynchrony in relation to left ventricular remodeling and function in hypertension. Int J Cardiol 179: 195200.

12. Gradman AH, Wilson JT (2009) Hypertension and diastolic heart failure. Curr Cardiol Rep 11: 422-429.

13. Gutierrez C, Blanchard DG (2004) Diastolic heart failure: Challenges of diagnosis and treatment. Am Fam Physician 69: 2609-2616.

14. Adebayo AK, Adebiyi AA, Oladapo OO, Ogah OS, Aje A, et al. (2009) Characterisation of heart failure with normal ejection fraction in a tertiary hospital in Nigeria. BMC Cardiovasc Disord 9: 52.

15. Ogah OS, Sliwa K, Akinyemi JO, Falase AO, Stewart S (2015) Hypertensive heart failure in Nigerian Africans: Insights from the Abeokuta Heart Failure Registry. J Clin Hypertens 17: 263-272.

16. McKee PA, Castelli WP, McNamara PM, Kannel WB (1971) The natural history of congestive heart failure: The Framingham study. N Engl J Med 285:1441-1446.

17. Williams B, Mancia G, Spiering W, Agabiti Rosei E, Azizi M, et al. (2018) 2018 ESC/ESH Guidelines for the management of arterial hypertension. Eur Heart J 39: 3021-3104.

18. Burballa C, Crespo M, Redondo-Pachon D, Perez-Saez MJ, Mir M, et al. (2018) MDRD or CKD-EPI for glomerular filtration rate estimation in living kidney donors. Nefrologia 38: 207-212.

19. https://www.who.int/nutrition/publications/en/ida_assessment_prevention_control.pdf
20. Lang RM, Badano LP, Mor-Avi V, Afilalo J, Armstrong A, et al. (2015) Recommendations for cardiac chamber quantification by echocardiography in adults: An update from the American Society of Echocardiography and the European Association of Cardiovascular Imaging. European heart journal Cardiovascular Imaging 16: 233-271.

21. Nagueh SF, Smiseth OA, Appleton CP, Byrd BF, Dokainish $\mathrm{H}$, et al. (2016) Recommendations for the evaluation of left ventricular diastolic function by echocardiography: An update from the american society of echocardiography and the european association of cardiovascular imaging. Eur Heart J Cardiovasc Imaging 17: 1321-1360.

22. Tocci G, Sciarretta S, Volpe M (2008) Development of heart failure in recent hypertension trials. J Hypertens 26: 14771486.

23. Ho KK, Pinsky JL, Kannel WB, Levy D (1993) The epidemiology of heart failure: The framingham study. J Am Coll Cardiol 22: 6A-13A.

24. Levy D, Larson MG, Vasan RS, Kannel WB, Ho KK (1996) The progression from hypertension to congestive heart failure. JAMA 275: 1557-1562.

25. Pfeffer MA, Shah AM, Borlaug BA (2019) Heart failure with preserved ejection fraction in perspective. Circ Res 124: 1598-1617.

26. Vasan RS, Larson MG, Benjamin EJ, Evans JC, Reiss CK, et al. (1999) Congestive heart failure in subjects with normal versus reduced left ventricular ejection fraction: Prevalence and mortality in a population-based cohort. J Am Coll Cardiol 33: 1948-1955.

27. Devereux RB, Roman MJ, Liu JE, Welty TK, Lee ET, et al. (2000) Congestive heart failure despite normal left ventricular systolic function in a population-based sample: The strong heart study. Am J Cardiol 86:1090-1096.

28. Shah RU, Klein L, Lloyd Jones DM (2009) Heart failure in women: Epidemiology, biology and treatment. Womens health 5: 517-527.

29. Lawson CA, Zaccardi F, Squire I, Ling S, Davies MJ, et al. (2019) 20-year trends in cause-specific heart failure outcomes by sex, socioeconomic status, and place of diagnosis: A population-based study. The Lancet Public health 4: e406-e420.

30. Meagher $P$, Adam M, Civitarese R, Bugyei Twum A, Connelly KA (2018) Heart failure with preserved ejection fraction in diabetes: Mechanisms and management. Can J Cardiol 34:632-643.

31. Komamura K (2013) Similarities and differences between the pathogenesis and pathophysiology of diastolic and systolic heart failure. Cardiol Res Pract 2013: 824135.

32. Ouzounian M, Lee DS, Liu PP (2008) Diastolic heart failure: Mechanisms and controversies. Nature Clinical Practice Cardiovascular Medicine 5: 375-386. 